\title{
Resección por videotoracoscopia de un quiste hidatídico mediastínico
}

\section{Video-assisted resection of a mediastinal hydatid cyst}

\author{
W. Torre, A. Tamura, E. Querejeta, U. Pila
}

\section{Sr. Director:}

La hidatidosis es una parasitosis producida por las larvas de Echinococcus granulosus, que parasita el intestino delgado del perro. Produce lesiones quísticas principalmente en el hígado y el pulmón y raramente en otras localizaciones. Suele tratarse de quistes asintomáticos, excepto por el efecto ocupante de espacio en las estructuras donde asienta. En caso de rotura, se diseminan los escólex, que producen una reacción anafiláctica ${ }^{1}$. Debido al riesgo de complicaciones está indicada la extirpación quirúrgica ${ }^{2,3}$, optándose por técnicas de cirugía abierta (toracotomía, esternotomía) en caso de quistes intratorácicos.

Comunicamos un caso de resección por videotoracoscopia de un quiste hidatídico mediastínico. Se trata de una paciente de 53 años para evaluar el tratamiento quirúrgico de un quiste hidatídico. Acudió dos meses antes con dolor tipo molestia sorda, urente, en zona costal izquierda inframamaria y zona axilar. Refería un ante- cedente de resección de quiste hidatídico en hemitórax izquierdo cuando tenía 10 años.

Se identificó por TAC una imagen de lesión quística compleja de 2,4 x 1,8 cm en mediastino anterior, en el ángulo cardiofrénico izquierdo. Presentaba una calcificación en cáscara, periférica, posterior, con un área de mayor densidad subyacente a la misma y un componente predominantemente hipodenso central. No se identificaron adenopatías macroscópicas supraclaviculares, axilares ni mediastínicas (Fig. 1).

Se pautó albendazol $400 \mathrm{mg} /$ día, pruebas de función hepática cada 15 días y se planteó la resección quirúrgica. El estudio preoperatorio incluye: analítica completa que refleja hematocrito de $41,2 \%$, hemoglobina $13,9 \mathrm{~g} / \mathrm{dL}$ y leucocitos $5,6 \mathrm{x} 10^{9} / \mathrm{L}$ (monocitos $12,6 \%$ y eosinófilos $1,8 \%$ ). Son normales las pruebas de función hepática, VSG, creatinina, TP y TTPA, electrocardiograma y pruebas de función respiratoria.
Servicio de Cirugía Torácica. Clinica Universidad de Navarra. Pamplona

Recepción: 3 de mayo de 2011

Aceptación provisional: 9 de junio de 2011

Aceptación definitiva: 24 de junio de 2011

\section{Correspondencia:}

Wenceslao Torre Buxalleu Servicio de Cirugia Torácica Clínica Universidad de Navarra Avda. Pio XII, 36 31008 Pamplona

E-mai.: wtorre@unav.es 


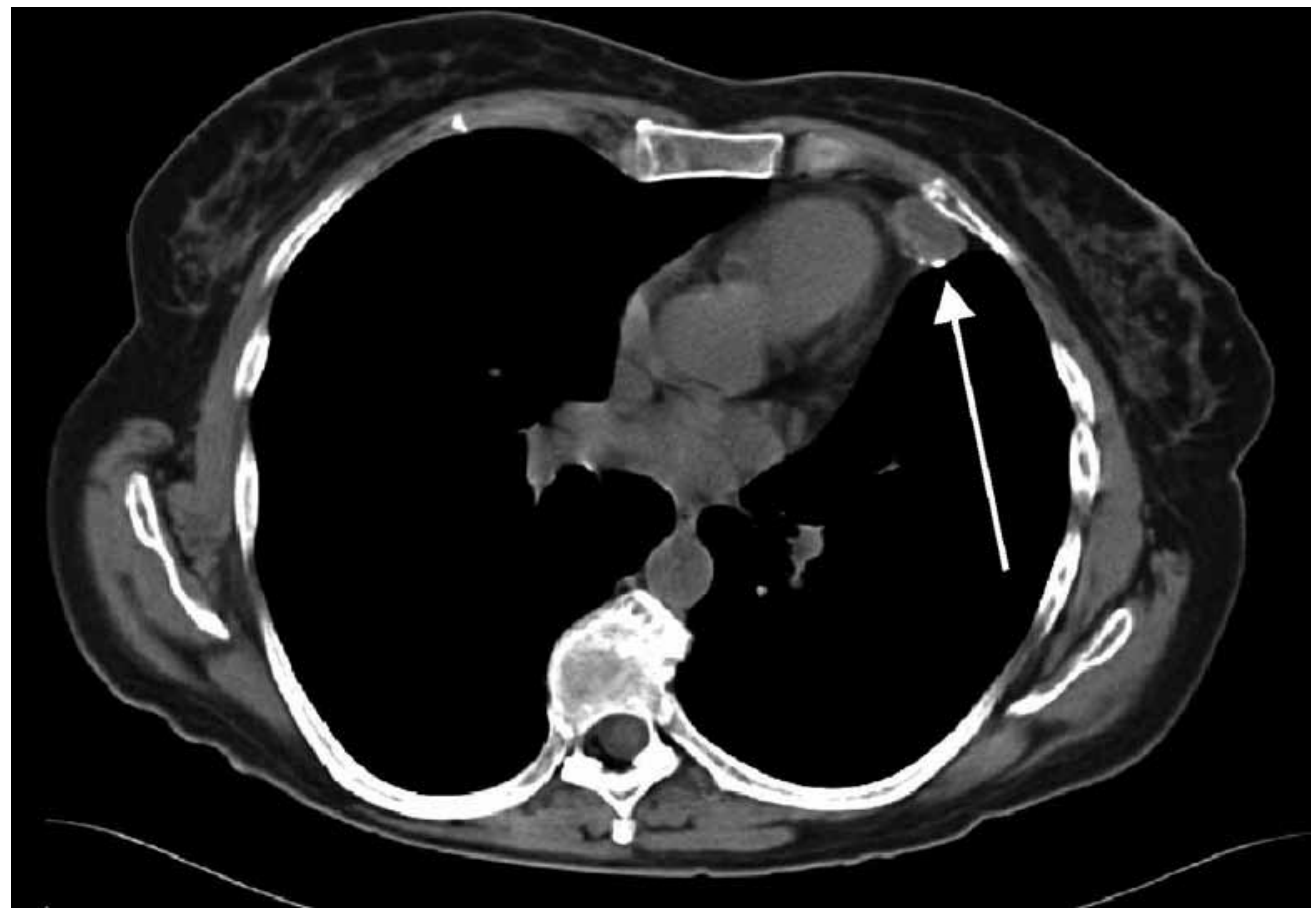

Figura 1. TAC torácico con lesión quística (flecha). Tomografía axial computarizada cerebral simple al ingreso demostrando imagen hiperdensa, semilunar hemisférica izquierda (se observan además artefactos por movimientos del paciente).

Se realiza una videotoracoscopia izquierda por tres vías. Se identifica el mediastino anterior. En el interior de la grasa tímica se palpa una lesión de unos $4 \mathrm{~cm}$ de diámetro que corresponde con el quiste. Éste se disecciona y se extrae la pieza a través de uno de los orificios mediante endobolsa, dejando un drenaje torácico con Pleur-Evac (que se retiró a las 24 horas sin incidencias). El informe anatomopatológico califica la pieza como un quiste hidatídico en cuyo interior se observan múltiples membranas anistas eosinófilas y abundante material necrótico con numerosos cristales de colesterol. Se establece la serología por hemaglutinación indirecta como negativa (Título $<80$ ), aunque se continúa el tratamiento con albendazol hasta completar 28 días. Al finalizar dicho plazo, se objetivaron valores de PCR normal, VSG de $37 \mathrm{~mm}$ y transaminasas elevadas (GOT 298 U/L y GPT 538 U/L). La serología se mantiene negativa. Las pruebas de función respiratoria no mostraron cambios significativos.

La hidatidosis es una parasitosis producida por Echinococcus granulosus, que parasita el intestino delgado del perro, por lo que la infección en los seres humanos es accidental. La gran mayoría de las larvas quedan atrapadas en el hígado (50$75 \%)$ o en el pulmón $(15-25 \%)^{1,3,4}$. Sólo un pequeño porcentaje $(<10 \%)^{3,5}$ logran atravesar el filtro hepático y pulmonar y afectar a otros órganos, principalmente bazo, riñón, páncreas, cerebro y corazón ${ }^{6}$ ). En muy raras ocasiones, llegará a otras localizaciones, como el mediastino ${ }^{1,2}$. Suele tratarse de quistes asintomáticos, excepto cuando su tamaño y el efecto ocupante de espacio afectan a las estructuras donde asienta $^{2,5}$. La ruptura, ya sea espontánea o iatrogénica, disemina los escólex produciendo hidatidosis secundarias y provo- 
cando una reacción anafiláctica de intensidad variable.

La clínica, la epidemiología (antecedente de contacto estrecho con perros) y la eosinofilia orientan el diagnóstico. El quiste se localiza por técnicas de imagen, siendo de elección la ecografía y la $\mathrm{TC}^{5}$ y completándose el estudio con pruebas serológicas. El diagnóstico se confirma mediante la visualización de escólex en la pieza quirúrgica, ya que la punción diagnóstica está siempre desaconsejada.

Convencionalmente la cirugía ha sido el tratamiento de elección. Con alta frecuencia la resección completa es posible con relativamente baja morbilidad y mortalidad. El índice de recidiva por siembra de escólex varía de 9,5 a $30 \%^{3,6}$, disminuyendo si se irriga el campo quirúrgico con escolicidas en el intraoperatorio y continuándose con tratamiento oral postquirúrgico. La aplicación aislada de albendazol terapéutico tiene una tasa de éxito limitada ${ }^{3,4}(30 \%$ en tratamientos de 3 a 6 meses de duración). Por ello se reserva para pacientes no aptos a cirugía. El albendazol como adyuvante a la cirugía reduce el tamaño y los síntomas asociados al quiste.

Las complicaciones de la cirugía son hidatidosis secundaria y reacción anafiláctica. Sobre el albendazol, los principales efectos adversos comprenden: alteraciones gastrointestinales (dolor abdominal, náuseas y vómitos), malestar general (fiebre, cefalea y vértigo) y hepatobiliares (aumento de enzimas hepáticas, hepatitis). La literatura previa no establece protocolos respecto a la cirugía abierta contra cerrada en el caso de quistes hidatídicos mediastínicos ${ }^{4}$. Por ende, podemos afirmar que ésta es una técnica en desarrollo. Queda al buen juicio del cirujano decidir la vía de abordaje; proponemos considerar los siguientes criterios: localización del quiste, tamaño y estadio, así como su número y extensión; características del paciente; ex- periencia del cirujano y deseo del paciente. La endoscopia posee menor morbilidad y tiempo de hospitalización, menos riesgo de complicaciones en el postoperatorio y mejor resultado estético ${ }^{4}$. Todo ello, nos lleva a inclinarnos por el uso de la VATS (Cirugía Torácica Vídeo Asistida) siempre que sea posible, y más aún en pacientes no candidatos a la toracotomía abierta, que por su mayor morbilidad podría conllevar una desfavorable relación riesgo-beneficio.

Proponemos que, a igual riesgo de complicaciones, la técnica de elección puede ser la videotoracoscopia. En cuanto a la profilaxis de hidatidosis secundaria y el uso de Albendazol como adyuvante a la cirugía, nada indica que las pautas deban ser distintas a las utilizadas en la resección del quiste mediante toracotomía.

\section{BIBLIOGRAFÍA}

1. Ülkü R, EREN N, ÇaKir Ö, Balci A, Onat S. Extrapulmonary intrathoracic hydatid cysts. J Can Surg 2004; 47: 95-98.

2. Traibi A, Atoin F, Zidane A, Arsalane A, Kabiri el H. Mediastinal hydatid cyst. J Chin Med Assoc 2010, 73: 3-7.

3. Tor M, Atasalihi A, Altuntas N, Sulu E, Senol T, KIR A et al. Review of cases with cystic hydatid lung disease in a tertiary referral hospital located in an endemic region: a 10 years' experience. Respiration 2000; 67: 539-542.

4. Mehta KD, Gundappa R, Contractor R, Sangani V, Pathak A, Chawda P. Comparative evaluation of thoracoscopy versus thoracotomy in the management of lung hydatid disease world. J Surg 2010; 34: 1828-1831.

5. Álvarez C, Riveros P, Miranda R, Yarur O. Quiste hidatídico mediastínico. Reporte de un caso y revisión de la literatura. Rev Chil Infect 2007; 24: 149-152.

6. Gursoy S, Ucvet A, Tozum H, Erbaycu AE, Kul C, BASOK O. Analysis of 14 patients with a rare clinical entity. Primary intrathoracic extrapulmonary hydatid cysts. Tex Heart Inst J 2009; 36: 230-233. 